\title{
Study of effect of chromium on titanium dioxide phase transformation
}

\author{
A BELLIFA*, L PIRAULT-ROY ${ }^{\dagger}$, C KAPPENSTEIN ${ }^{\dagger}$ and A CHOUKCHOU-BRAHAM ${ }^{\dagger \dagger}$ \\ Laboratory of Materials, Application and Environment; University of Mascara, Mascara, Algeria \\ ${ }^{\dagger}$ Laboratory of Catalysis in Organic Chemistry, University of Poitiers, Poitiers, France \\ ${ }^{\dagger}$ Laboratory of Catalysis and Synthesis in Organic Chemistry, University of Tlemcen, Algeria
}

MS received 23 February 2013

\begin{abstract}
MTiX samples with different atomic chromium percentages were synthesized by sol-gel method and calcined at $400{ }^{\circ} \mathrm{C}$ under air. The effects of $\mathrm{Cr}$ and temperature on titanium dioxide phase transition were studied. In situ measurement showed the presence of anatase phase for all samples at temperature $<500{ }^{\circ} \mathrm{C}$. Without $\mathrm{Cr}$ content, the anatase-rutile transition takes place at $600{ }^{\circ} \mathrm{C}$ and the rutile fraction increases with increase of temperature. In the presence of $\mathrm{Cr}$ content, rutile phase appeared at $700{ }^{\circ} \mathrm{C} . \mathrm{Cr}_{2} \mathrm{O}_{3}$ phase was shown only in the case of $\mathrm{CrTi} 20$ content at $800{ }^{\circ} \mathrm{C}$ which indicates that the segregation remains modest. We have also studied the anatase-rutile transition kinetics by using in situ $\mathrm{X}$-ray measurements. It was found that the anatase phase stability increases as the chromium content increases. Results confirm that the transformation of anatase-rutile is of first order.
\end{abstract}

Keywords. Mixed oxides; $\mathrm{TiO}_{2}$; transition anatase-rutile; kinetics; sol-gel; XRD.

\section{Introduction}

Titanium dioxide $\left(\mathrm{TiO}_{2}\right)$ has attracted increasing attention because of its wide applications in many fields such as supports, catalysts and particularly in degrading various organic and inorganic environmental pollutants (Bacsa and Kiwi 1998; Barakat et al 2005; Lee et al 2005; Pavasupree et al 2005; Ma et al 2010; Zhang et al 2011; Zhuang et al 2011). In general, for all applications, an important surface of contact is needed between the reactants and $\mathrm{TiO}_{2}$. The anatase phase shows higher photocatalytic activity than rutile due to its high crystallinity and large specific surface area which are desirable parameters in photocatalytic reactions (Rajesh Kumar et al 2000; Wang et al 2004).

As we know, the anatase phase is less stable than rutile phase which is thermodynamically more stable. Anatase is typically the major product of inorganic syntheses and main constituent of nanocrystalline materials. The transformation from anatase to rutile phase can take place by just increasing in the heating temperature which decreases the surface area. It has been reported that titania normally undergoes anatase-rutile phase transformation in the temperature range from 600 to $800{ }^{\circ} \mathrm{C}$ and this phase transition has been widely studied from the point of view of both scientific interest and technological applications (Hu et al 2003a, b; Pillai et al 2007; Riays et al 2007; Aldabergenova et al 2008; Gambhire et al 2008; Wetchakun and Phanichphant 2008; Houskova et al 2009).

*Author for correspondence (abellifa@ yahoo.fr)
Several authors and researchers have attempted to understand the anatase-rutile transition (Ha et al 2000; Zhang and Banfield 2000; Djaoued et al 2002; Chao et al 2003; Zhu et al 2005). This transition depends on several parameters such as the preparation techniques used, preparation conditions, thermal treatments, alkoxide nature, particle size, aging, nature and content of possible doping agents (Mahanty et al 2004; Zhang 2005; Zhang and Banfield 2005; Bellifa et al 2006; Setiawati and Kawano 2008). It was shown that anatase phase becomes more stable than rutile phase when the particles size decreases (Zhang and Banfield 1998; Li et al 2004). On the other hand, the effect of solution $\mathrm{pH}$ in phase stability for $\mathrm{TiO}_{2}$ has been studied (Finnegan et al 2007). It was shown that at small sizes, rutile is stabilized relative to anatase in acidic solutions, whereas in basic solutions anatase is stabilized relative to rutile. The doping metal oxides can be added by different ways such as further impregnations or mixed powders, but the best effect is obtained by a close contact between the stabilizing element and oxide (Arroyo et al 2002; Reidy et al 2005). To optimize this interaction, many studies focused on doped $\mathrm{TiO}_{2}$ prepared by various methods. The titania-silica samples were prepared by sol-gel hydrothermal (SGH) and sol-gel (SG) methods. The results show that the samples prepared by SGH had better thermal stability compared with SG samples which retard the anataserutile transformation ( $\mathrm{Li}$ et al 2005). On the other hand, Zhang (2005) has used the titanium oxide doped with silica for photodegradation of toluene. The sample was prepared by sol-gel method and it has found that the 
embedding of small amount of silica into anatase-titania matrix enhanced the thermal stability of nanophasetitania particle resulting in the suppression of the phase transformation from anatase to rutile phase. The ionic liquid was also used by Yoo et al (2004) for the synthesis of titanium oxide at an ambient temperature. The porous volume and BET specific surface of $\mathrm{TiO}_{2}$ decrease from 0.296 to $0.207 \mathrm{~cm}^{3} \mathrm{~g}^{-1}$ and from 282 to $47.9 \mathrm{~m}^{2} \mathrm{~g}^{-1}$, respectively, upon heat treatment from 20 to $800^{\circ} \mathrm{C}$ and all crystalline materials were in the anatase phase.

It is found that, in the case of gallia-titania mixed oxide prepared via coprecipitation method, no diffraction lines due to the rutile phase are observed with increasing temperature from 500 to $800{ }^{\circ} \mathrm{C}$. Therefore, when the concentration of copper is high $(5 \mathrm{~mol} \%)$, copper segregation inhibits the anatase-rutile transition, whereas, it has found that when manganese ions are added in low concentration, the anatase phase is stabilized (Reddy et al 2001; Baltazar et al 2006).

A clear understanding of the key factors that control the phase stability, growth, and phase transformation kinetics in materials is critical to quantification of materials behaviour. Consequently, new understanding of the factors that dictate the sequence of the phase transformations may provide insights into how phase composition, microstructures and properties of titania-based materials can be manipulated (Zhang and Banfield 2000).

In this paper, we report the sol-gel synthesis of CrTiX mixed oxides with $X=0,5,10$ and 20 of chromium atom percentage. We study the effect of the weight chromium content on the temperature of the anatase-rutile transition and the kinetic order of the transformation by in situ XRD.

\section{Experimental}

\subsection{Materials}

Titanium tetrabutoxide $\left(\mathrm{Ti}\left(\mathrm{OC}_{4} \mathrm{H}_{9}\right)_{4} ;\right.$ Aldrich, 97\%), chromium (III) nitrate nanohydrate $\left(\mathrm{Cr}\left(\mathrm{NO}_{3}\right)_{3} \cdot 9 \mathrm{H}_{2} \mathrm{O}\right.$; Aldrich, 99\%), nitric acid (65 wt\%) and absolute ethanol were employed for the preparation of different samples of $\mathrm{CrTiX}$. The atomic percentage of chromium is defined as follows: $X=100[n(\mathrm{Cr}) /(n(\mathrm{Cr})+n(\mathrm{Ti}))]$.

\subsection{Synthesis procedure}

The preparation of $\mathrm{TiO}_{2}$ was carried out in a $100 \mathrm{~mL}$ beaker. Titanium butoxide was dissolved in absolute ethanol. The mixture was stirred for $30 \mathrm{~min}$ and then a solution of ethanol and nitric acid was added drop-wise into the mixture. A white gel was obtained which is dried in a sand bath at $60{ }^{\circ} \mathrm{C}$ for $6 \mathrm{~h}$, then in an oven at $120^{\circ} \mathrm{C}$ for a night. The sample was calcined in a muffle furnace at $400{ }^{\circ} \mathrm{C}$ for $4 \mathrm{~h}$ under air atmosphere.
The samples of $\mathrm{CrTi} X$ were prepared in the same way as adopted for $\mathrm{TiO}_{2}$ with the addition of an aqueous solution of chromium nitrate before the addition of nitric acid solution to get the final chromium contents of 5, 10 and $20 \%$. The samples were called $\mathrm{MTi}_{5}, \mathrm{MTi}_{10}$ and $\mathrm{MTi}_{20}$ for 5,10 and 20 of chromium atom percentage, respectively.

\subsection{Samples characterization}

Micrometrics Tristar 3000 instrument was used to measure adsorption-desorption isotherms at liquid nitrogen temperature to determine specific surface, porous volume and mean pore size from BJH method. The samples calcined at $400{ }^{\circ} \mathrm{C}$, were outgassed at $90{ }^{\circ} \mathrm{C}$ for $1 \mathrm{~h}$ then at $350{ }^{\circ} \mathrm{C}$ for $10 \mathrm{~h}$ under secondary vacuum before measurements.

Thermogravimetric analysis (TGA) and differential thermal analysis (DTA) were performed on powders (15$30 \mathrm{mg}$ ) from room temperature to $1000{ }^{\circ} \mathrm{C}$ using a Thermal Analyst STD 2960 TA Instruments. Samples were heated at a rate of $10{ }^{\circ} \mathrm{C} \mathrm{min}{ }^{-1}$ for measurements under dry air flow.

The crystalline phases of the samples were identified by X-ray powder diffraction (XRD) using Bruker D8ADVANTED diffractometers with $\mathrm{CuK} \alpha$ radiation $\left(\lambda \mathrm{K}_{\alpha_{1}}=0.15406 \mathrm{~nm}\right)$. The diffractograms were obtained under the following conditions:

Dwell time: $2 \mathrm{~s}$; step: $0 \cdot 04^{\circ} 2 \theta$, divergence slit: $0 \cdot 3^{\circ}$. The crystalline phases were identified by comparison with powder diffraction files (PDF) standards from ICDD (PDF number: $\mathrm{TiO}_{2}$ anatase: $21-1272 ; \mathrm{TiO}_{2}$ rutile: $21-$ 1276). The crystallite sizes were determined from the Scherrer equation (Popa et al 2005) using the integrated width corrected from apparatus using $\mathrm{LaB}_{6}$ as a standard.

For the kinetic study, XRD profiles are collected in $2 \theta$ range between 20 to $32^{\circ}$. A thin layer of the powdered oxide (about $20 \mathrm{mg}$ ) is deposited on a Kanthal ( $\mathrm{Fe}-\mathrm{Cr}$ alloy) ribbon heated by the Joule effect. The samples are heated under air from ambient to target temperatures at a heating rate of $5^{\circ} \mathrm{C} \mathrm{s}^{-1}$. At the end, they are subsequently cooled down at ambient temperature (normal cooling).

\section{Results and discussion}

\subsection{Structural data}

Titanium dioxide $\left(\mathrm{TiO}_{2}\right)$ can exist in three major different crystal structures: brookite, anatase and rutile. For all structures, the titanium is surrounded by six oxygen atoms in a distorded octahedral geometry.

The rutile phase has the same structure-like anatase phase; with the exception that there are two and four edges of each octahedron are shared in rutile and anatase, respectively. In rutile, the bridge bond is connecting two equatorial oxygen atoms. The octahedra are hence form- 
ing vertical linear chains. The octahedra belonging to adjacent chains are connected only through one corner: an oxygen atom which is at the same time, apical and equatorial for the two touching octahedra. In anatase, the octahedra are arranged in order to share a diagonal edge between an apical and an equatorial atom. Octahedra are hence forming zig-zag chains orthogonal to the crystallographic axis. There are two sets of chains orthogonal to each other and connected through a common octahedron.

The packing of $\mathrm{TiO}_{6}$ octaheders is the main factor to explain the anatase-rutile transition. For anatase, we have 4 octaheders at a distance of $3.04 \AA$, whereas rutile displays only two octaheders at $2.96 \AA$ despite a higher density. The distance between the centre of edge sharing
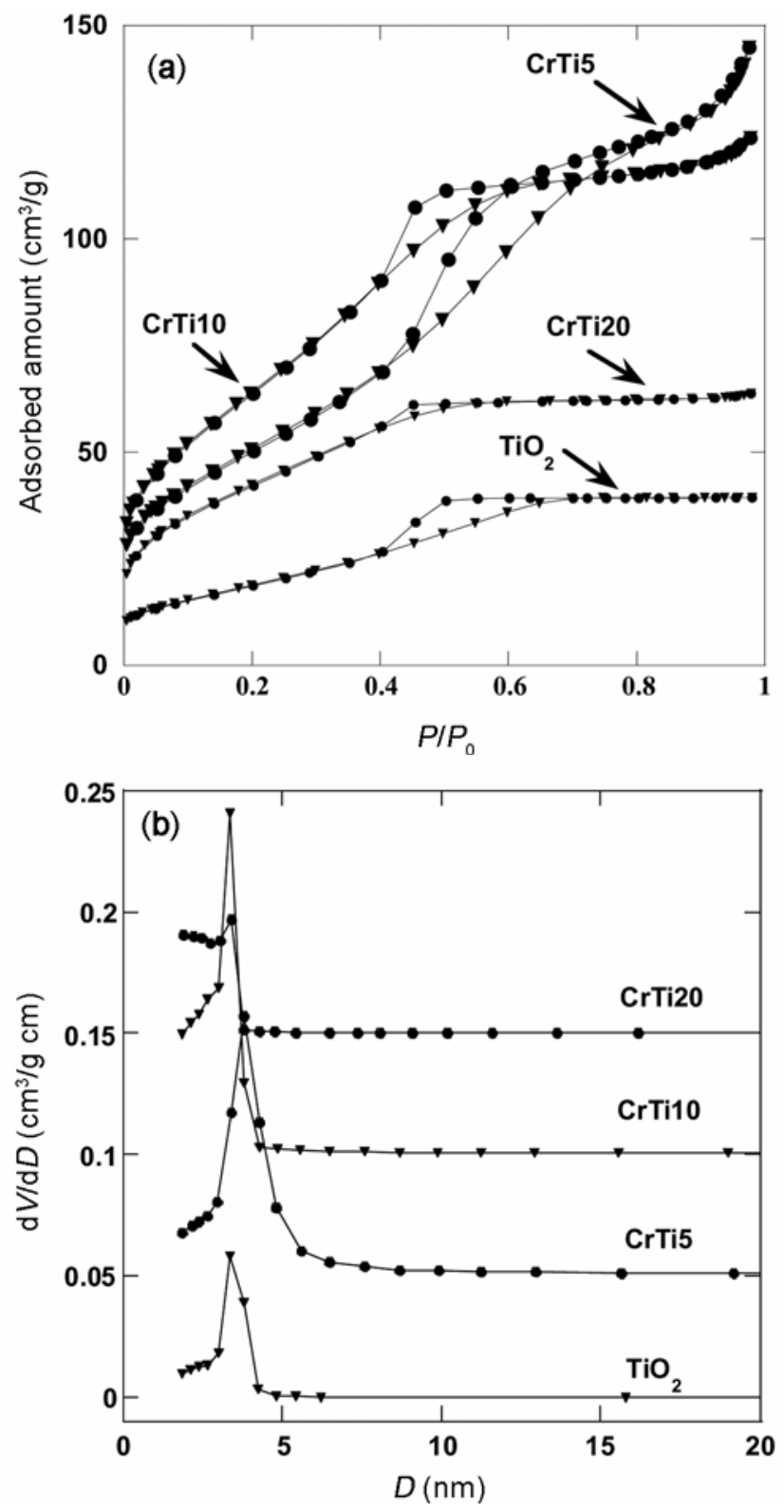

Figure 1. (a) Isotherms for adsorption of nitrogen on CrTiX samples and (b) pore size distributions measured in samples. octahedra (the shortest Ti-Ti distance) is smaller in rutile than in anatase. On the other hand each $\mathrm{Ti}$ atom in rutile has only two Ti atoms at the closest distance. This leads to strong and unidirectional $\mathrm{Ti}-\mathrm{Ti}$ interaction. In anatase, $\mathrm{Ti}-\mathrm{Ti}$ distance is larger than rutile but, the Ti-Ti interaction depends on four-nearest $\mathrm{Ti}$ atoms instead of two. The important $\mathrm{Ti}-\mathrm{O}-\mathrm{Ti}$ interaction is qualitatively quite different in the two structures. The increased Ti-Ti distance in anatase is associated with a shorter bridge-bond length (the shortest $\mathrm{O}-\mathrm{O}$ distance). The weaker covalent $\mathrm{Ti}-\mathrm{Ti}$ interaction tends to favour indirectly the $\mathrm{O}-\mathrm{O}$ bridgebond or vice versa, the bridge bond is shortened in order to increase the $\mathrm{Ti}-\mathrm{Ti}$ interaction by putting more charge in the middle. Therefore, anatase exhibits a higher congestion around each $\mathrm{TiO}_{6}$ units and the driving force of the transition could be the relaxation of this congestion leading to more stable rutile.

\subsection{Textural data}

$\mathrm{N}_{2}$ adsorption-desorption isotherms of the different samples are reported in figure 1(a). The isotherm profile for all the samples corresponds to a type IV with the presence of a hysteresis loop indicating the existence of mesopores in the samples. A sharp increase in adsorption volume of $\mathrm{N}_{2}$ was observed in $P / P_{0}$ range of $0.4-0.8$ and can be assigned to the capillary condensation, indicating good homogeneity of the samples. As illustrated in figure 1 (b), the pore size distribution is quite narrow $(3-5 \mathrm{~nm})$, indicate good quality of the products.

The values of specific surface, pore volume and pore size are shown in table 1 . The specific surface area increases with increasing content of chromium. With an excess of chromium content $(20 \%)$, the specific surface decreases to $152 \mathrm{~m}^{2} \mathrm{~g}^{-1}$. This last result can be explained by probable segregation of chromium and formation of CrOx clusters (Arroyo et al 2002; Niemeyer et al 2002; Ruiza et al 2003; Sreethawong et al 2005). The average pore size of anatase phase decreases with increase of chromium content. It is known that anatase phase is more stable with small particle sizes (Zhang and Banfield 1998; Li et al 2004; Zhang and Banfield 2005); so the presence of chromium stabilize the anatase phase.

\subsection{Thermal analysis}

The thermals analysis of $\mathrm{TiO}_{2}$ before calcination is illustrated in figure 2. The total weight loss of around $17 \%$ was observed between 20 and $1000^{\circ} \mathrm{C}$ in TG curve which was involved in two stages between 20 and $200{ }^{\circ} \mathrm{C}$ and between 200 and $400{ }^{\circ} \mathrm{C}$. DTA curve shows one endothermic and two exothermic peaks. The endothermic peak is attributed to desorption of water physisorbed. The first-exothermic peak at $251{ }^{\circ} \mathrm{C}$, is attributed to the removal by oxidation of the precursor $\mathrm{Ti}$ (alkoxide) and the 
Table 1. Surface area, porous volume and pore size of samples.

\begin{tabular}{lccc}
\hline Samples & $S_{\text {BET }}\left(\mathrm{m}^{2} \cdot \mathrm{g}^{-1}\right)$ & Pore volume $\left(\mathrm{cm}^{3} \cdot \mathrm{g}^{-1}\right)$ & Average pore size $(\mathrm{nm})$ \\
\hline $\mathrm{TiO}_{2}$ & 68 & $0 \cdot 06$ & $3 \cdot 60$ \\
$\mathrm{CrTi}_{5}$ & 180 & $0 \cdot 22$ & $5 \cdot 00$ \\
$\mathrm{CrTi}_{10}$ & 230 & $0 \cdot 19$ & $3 \cdot 30$ \\
$\mathrm{CrTi}_{20}$ & 152 & $0 \cdot 10$ & $2 \cdot 60$ \\
\hline
\end{tabular}

Samples calcined at $400{ }^{\circ} \mathrm{C}$.

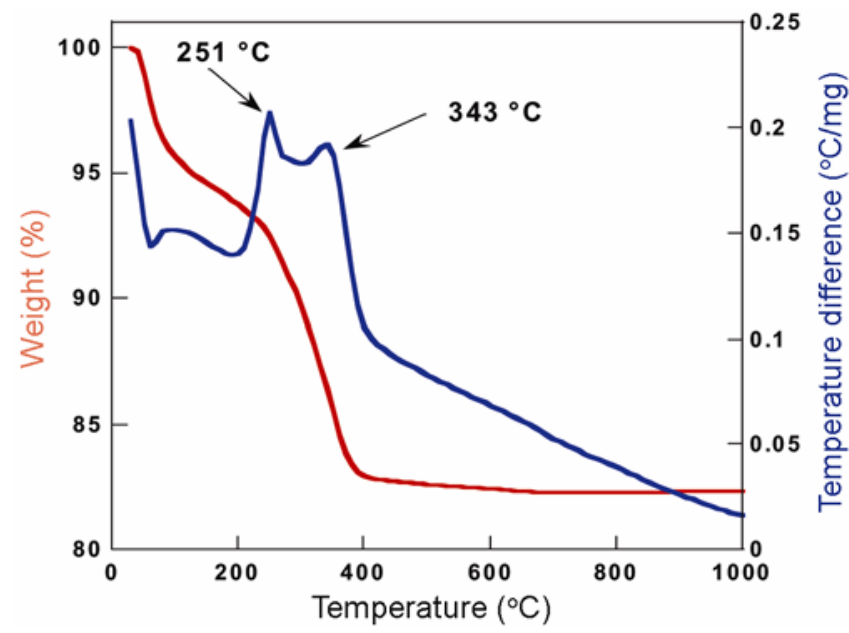

Figure 2. TGA-DTA curves of $\mathrm{TiO}_{2}$ before calcination.

second-exothermic peak at $343{ }^{\circ} \mathrm{C}$ corresponds to the passage of titanium oxide from the amorphous to the anatase phase (Jiang and Chen 2004).

For the samples calcined at $400{ }^{\circ} \mathrm{C}$ (materials supplementary), the curves display one endothermic peak in the range of $0-200{ }^{\circ} \mathrm{C}$, corresponding to desorption of water adsorbed on the surface; with a mass loss between 5 and $7 \%$. In the range of $0-400{ }^{\circ} \mathrm{C}$, we found a mass loss of 3.6, 9, 11 and $9 \%$ for $\mathrm{TiO}_{2}, \mathrm{CrTi}_{5}, \mathrm{CrTi}_{10}$ and $\mathrm{CrTi}_{20}$, respectively. On the other hand, the total weight loss observed between 400 and $800{ }^{\circ} \mathrm{C}$ was $0 \cdot 6,0 \cdot 6,0.94$ and $1.45 \%$ for $\mathrm{TiO}_{2}, \mathrm{CrTi}_{5}, \mathrm{CrTi}_{10}$ and $\mathrm{CrTi}_{20}$, respectively. Thus, this last result can be attributed to the presence of residual hydroxyl groups which are related to the increase of chromium content and can be removed by a temperature increase (Li et al 2011). No exothermic was observed which characterizes the anatase to rutile transition.

\section{$3.4 \quad X$-ray diffraction and kinetics study}

The measures of RXD analyses of CrTiX samples have been obtained in situ at different temperatures under vacuum. All the diffractograms have been obtained between 400 and $800{ }^{\circ} \mathrm{C}$ with $5^{\circ} \mathrm{C} / \mathrm{min}$ in $2 \theta$ range from 20 to $90^{\circ}$, with step of $0 \cdot 05^{\circ}$ and dwelling time of $2 \mathrm{~s}$. The diffractograms were recorded after cooling for $\mathrm{TiO}_{2}$ and in situ for $\operatorname{CrTi} X$ samples. The anatase phase is present for all samples at $400{ }^{\circ} \mathrm{C}$, no correponding pic for rutile, brookite and chromium phase (figures 3 and 4). The peak at $44^{\circ}$ of $2 \theta$ is attributed to Kanthal phase. For pure titanium dioxide $\left(\mathrm{TiO}_{2}\right)$, the rutile phase is observed at $600{ }^{\circ} \mathrm{C}$. The transformation anatase-rutile is total between 700 and $800{ }^{\circ} \mathrm{C}$. For Cr-doped titanium oxide, the rutile phase is absent after treatment at 400 to $500{ }^{\circ} \mathrm{C}$. At $800{ }^{\circ} \mathrm{C}$, the transformation remains partial and the rutile phase decreases with increase of chromium content. So the presence of chromium content increases the transition temperature and stabilizes more than anatase phase. The chromia phase $\left(\mathrm{Cr}_{2} \mathrm{O}_{3}\right)$ appeared at 700 and $800{ }^{\circ} \mathrm{C}$ for $\mathrm{CrTi}_{10}$ and $\mathrm{CrTi}_{20}$ indicating that the segregation remains modest.

The increase of rutile fraction with increasing temperature for samples was calculated using the following equation (Arroyo et al 2002; Li et al 2004; Setiawati and Kawano 2008):

$$
X_{\mathrm{r}}=\left[1+0 \cdot 8 I_{\mathrm{a}} / I_{\mathrm{r}}\right]^{-1},
$$

where $X_{\mathrm{r}}$ represents the weight fraction of rutile, $I_{\mathrm{r}}$ and $I_{\mathrm{a}}$ represent the integrated surface of rutile (110) and anatase (101) diffraction peaks, respectively.

In figure 5 , the fractions of rutile phase at $800{ }^{\circ} \mathrm{C}$ are 100, 47, 18 and $12 \%$ for $\mathrm{TiO}_{2}, \mathrm{CrTi}_{5}, \mathrm{CrTi}_{10}$ and $\mathrm{CrTi}_{20}$ respectively. These results lead to the conclusion that the presence of chromium inhibits the transformation of the anatase phase into rutile phase.

Table 2 illustrated the variation of the size of crystallite as a function of the temperature. A sintering of the anatase phase takes place with increasing of temperature from 400 to $800{ }^{\circ} \mathrm{C}$. On the other hand, the presence of chromium retards the sintering of the anatase phase, whereas in the case of rutile phase, the size of particles is independent of chromium content. The anatase phase is stable when the crystallite size is $<22 \mathrm{~nm}$. When the crystallite size is $>22 \mathrm{~nm}$, the anatase phase transforms into rutile phase which is more stable with larger crystallite size.

The kinetics of the anatase-rutile transition generally dependson fabrication and heat treatment conditions due to the metastable nature of the anatase phase. Thus, consideration at the state of anatase is necessary in discussing the difference in transition kinetics between powders with different processing histories. 

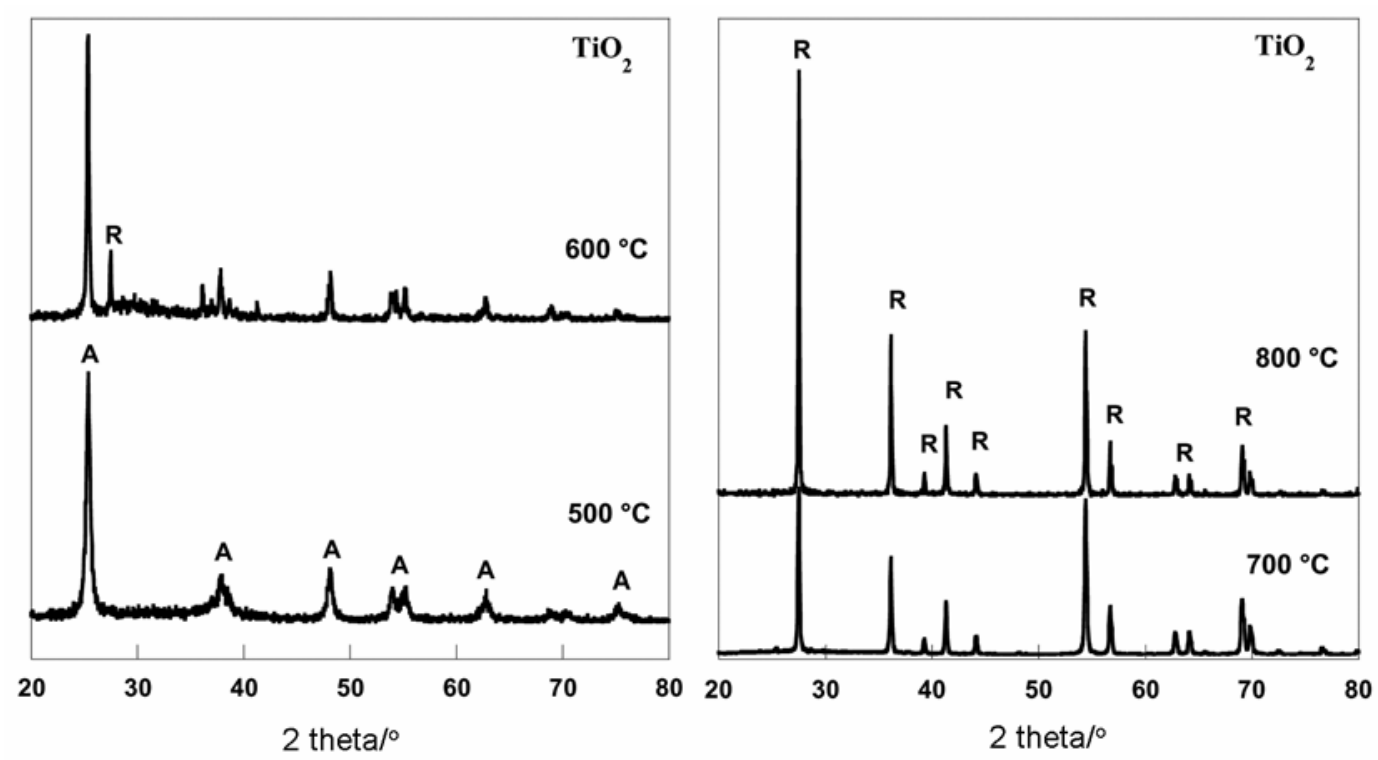

Figure 3. In situ XRD diffractograms of $\mathrm{TiO}_{2}$ and $\mathrm{A}$ : anatase and R: rutile.

Table 2. Crystallite size vs temperature.

\begin{tabular}{|c|c|c|c|c|c|c|c|c|}
\hline \multirow[b]{3}{*}{$\mathrm{T} /{ }^{\circ} \mathrm{C}$} & \multicolumn{8}{|c|}{ Crystallite size $(\mathrm{nm})$} \\
\hline & \multicolumn{2}{|c|}{$\mathrm{TiO}_{2}$} & \multicolumn{2}{|c|}{$\mathrm{CrTi}_{5}$} & \multicolumn{2}{|c|}{$\mathrm{CrTi}_{10}$} & \multicolumn{2}{|c|}{$\mathrm{CrTi}_{20}$} \\
\hline & $\mathrm{A}$ & $\mathrm{R}$ & $\mathrm{A}$ & $\mathrm{R}$ & A & $\mathrm{R}$ & A & $\mathrm{R}$ \\
\hline 400 & 10 & - & 07 & - & 06 & - & 06 & - \\
\hline 500 & 16 & - & 10 & - & 13 & - & 07 & - \\
\hline 600 & 27 & 41 & 16 & - & 13 & - & 09 & - \\
\hline 700 & 37 & 36 & 22 & 32 & 22 & - & 20 & - \\
\hline 800 & - & 40 & 32 & 37 & 32 & 39 & 30 & 35 \\
\hline
\end{tabular}

$\mathrm{A}$, anatase; $\mathrm{R}$, rutile and $\mathrm{T}$, temperature.

The anatase-rutile transition kinetics of samples was obtained at isothermal conditions under air. In this work, we present just only two isothermals at $650{ }^{\circ} \mathrm{C}$ and $750{ }^{\circ} \mathrm{C}$. Figure 6 shows quasi-total transformation of anatase phase on rutile phase only at $650{ }^{\circ} \mathrm{C}$ between 3 and $6 \mathrm{~h}$ for $\mathrm{TiO}_{2}$. The anatase phase remains the predominant phase at $750{ }^{\circ} \mathrm{C}$ after $10 \mathrm{~h}$ in the case of $\mathrm{CrTi}_{20}$. Thus, last results indicate that the speed of anatase-rutile transition is slowed by the presence of chromium.

The anatase-rutile transition kinetics of the mesoporous materials can be obtained by considering isothermic change in rutile and anatase rutile content. In this paper, we proposed two methods to calculate the kinetic order of anatase-rutile transition. We have suggested that the amount of the disappeara anatase phase was equal to the amount of formation rutile phase. We have supposed that the anatase-rutile transformation obey the first order kinetics according to the following equations:

$$
\begin{aligned}
& \operatorname{Anatase}(a) \rightarrow \operatorname{Rutile}(r), \\
& \frac{\mathrm{d} n_{\mathrm{a}}}{n_{\mathrm{a}}}=k \mathrm{~d} t \Rightarrow \ln I_{\mathrm{a}}=k t+l,
\end{aligned}
$$

where $I$ is the integral surface, $k$ the kinetics constant and $l$ the constant.

The generalized equation plot between $\ln I_{\mathrm{a}}$ and $k_{\mathrm{t}}$ is shown in figure 7(a). The curves revealed a straight line which seems to obey the first-order kinetics for anataserutile phase transition.

Existing kinetic models are unable to describe experimental data for the anatase-rutile transformation in samples. Due to the model of Avrami for nucleation and growth kinetics, the basic generalized Avrami equation can be expressed by (4) (Ha et al 2000; Sreethawong et al 2005):

$$
\ln \left[-\ln \left(1-X_{\mathrm{r}}\right)\right]=n \ln t+\ln k,
$$

where $X_{\mathrm{r}}$ is the rutile ratio calculated from (1), $t$ the heating time, $n$ the transition kinetics order and $k$ the transition kinetics constant.

In this paper we present only the case of $\mathrm{TiO}_{2}$ at $650{ }^{\circ} \mathrm{C}$ and $\mathrm{CrTi}_{5}, \mathrm{CrTi}_{20}$ at $750{ }^{\circ} \mathrm{C}$. The variation of $\ln [-\ln$ $\left.\left(1-X_{\mathrm{r}}\right)\right]$ vs time for all samples is shown in figure $7(\mathrm{~b})$. The correlation revealed a straight line with a slope equal to 1 for $\mathrm{TiO}_{2}, 0.8$ for $\mathrm{CrTi}_{5}$ and 1.09 for $\mathrm{CrTi}_{20}$, which 

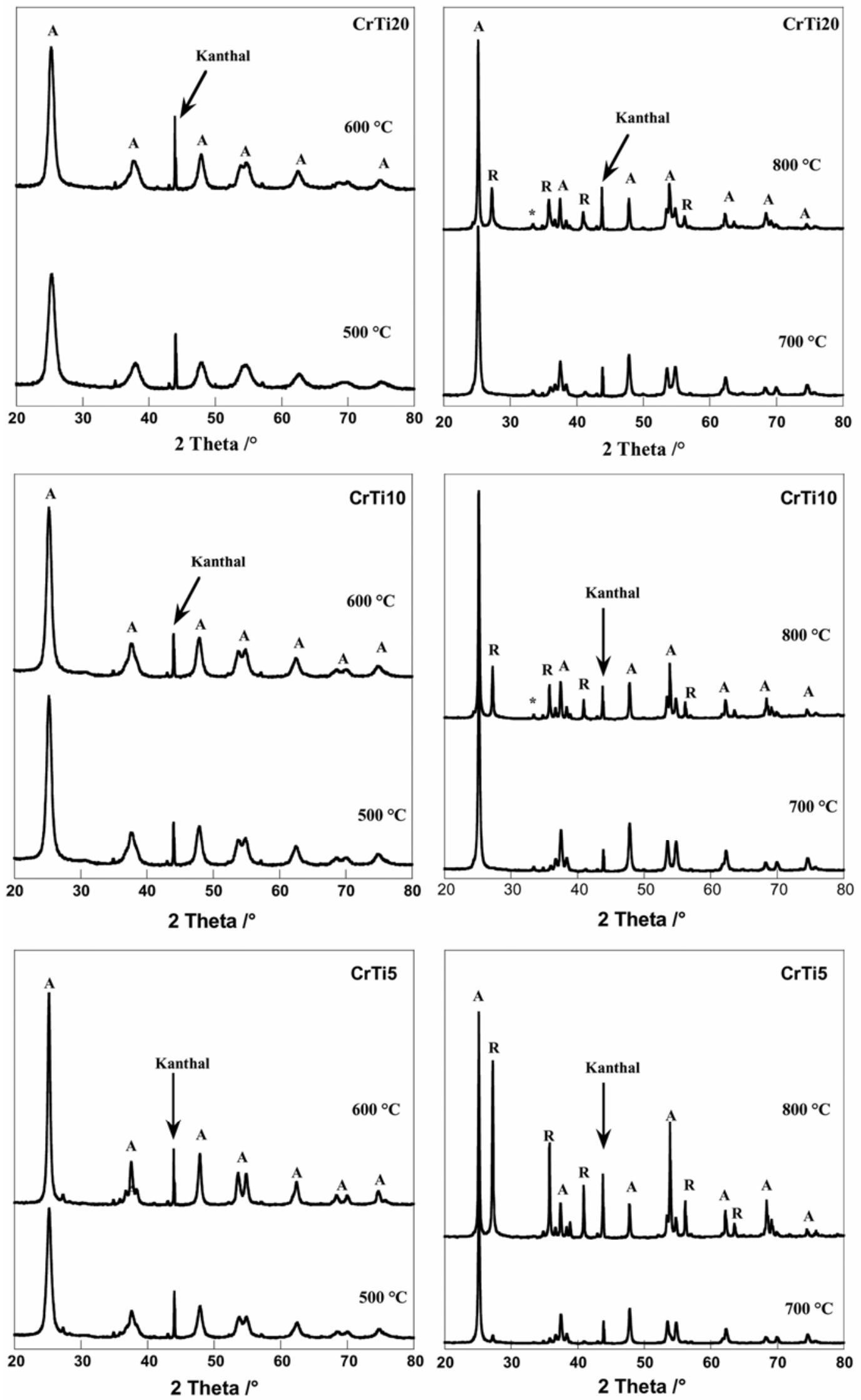

Figure 4. In situ XRD diffractograms of CrTiX; A: anatase; R: rutile and *: $\mathrm{Cr}_{2} \mathrm{O}_{3}$. 


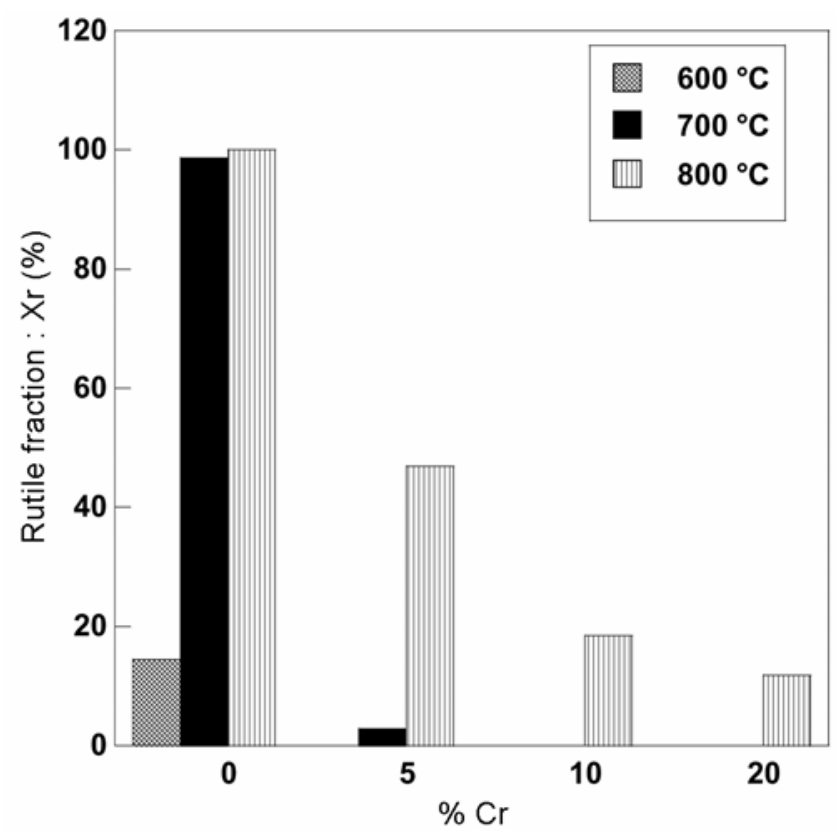

Figure 5. Variation of rutile fraction vs chromium content of samples.
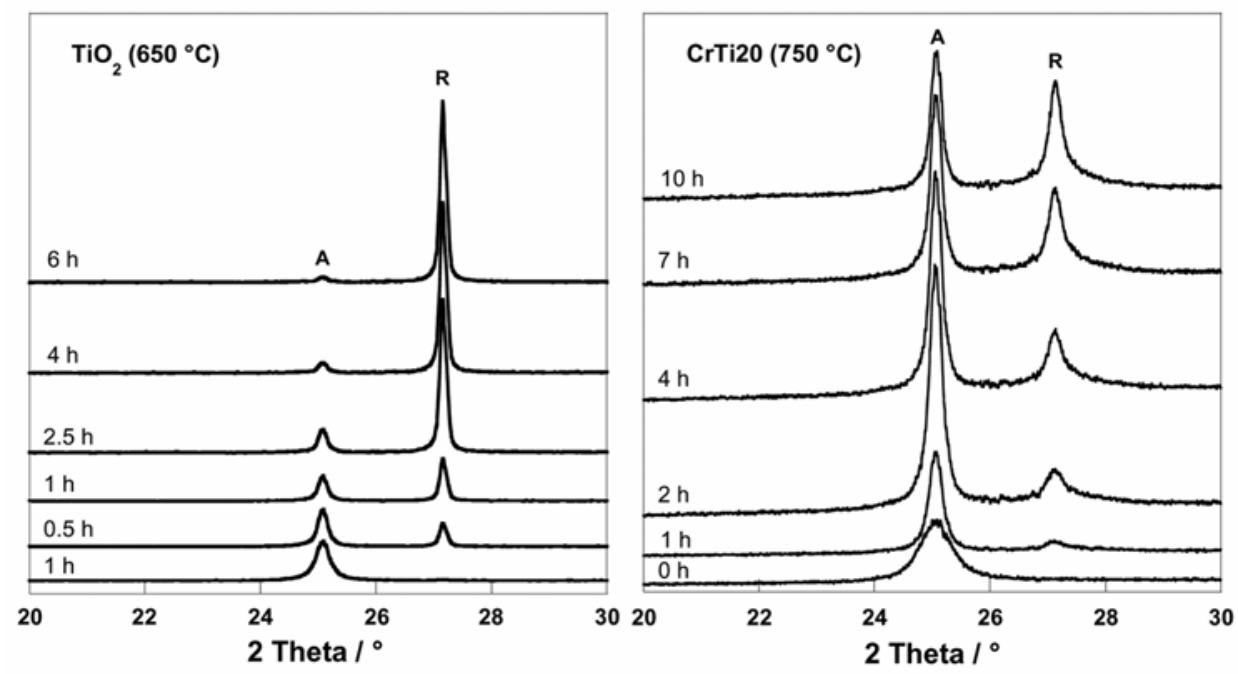

Figure 6. In situ XRD diffractograms of anatase-rutile transition vs time.

Table 3. Values of activation energy and pre-exponential factor.

\begin{tabular}{lcc}
\hline Samples & $E_{\mathrm{a}}\left(\mathrm{kJ} \mathrm{mol}^{-1}\right)$ & $10^{-6} \mathrm{~A}(1 / t)$ \\
\hline $\mathrm{TiO}_{2}$ & $263 \pm 10$ & 0.06 \\
$\mathrm{CrTi}_{5}$ & $375 \pm 10$ & 600 \\
$\mathrm{CrTi}_{20}$ & $308 \pm 10$ & 0.06 \\
\hline
\end{tabular}

A, pre-exponential factor (frequency factor).

seems to obey the first-order kinetics for anatase-rutile phase transition.

The apparent activation energy for the anatase-rutile transition was calculated by considering that kinetics constant $(k)$ obeys to the Arrhenius law as following:

$$
\begin{aligned}
& k=A \exp \left(-E_{\mathrm{a}} / R T\right), \\
& \ln k=\ln A-\left(E_{\mathrm{a}} / R\right) 1 / T,
\end{aligned}
$$

where $k$, kinetics constant; $E_{\mathrm{a}}$ activation energy; $T$, temperature; $R$, perfect gas constant and $A$, frequency factor.

In this study, we have changed for all samples between three and four values of temperature.

The variation of $\ln (k)$ vs $1 / T$ gives directly the values of activation energy. Figure 8 shows a straight with a good correlation coefficient $\left(R^{2}=0.99\right)$. The plots value leads to calculate activation energy. Table 3 are summing the value of activation energy for all samples. The values of pre-exponential factor are 0.06, 600 and $0.06 \times 10^{16} \mathrm{t}^{-1}$ 

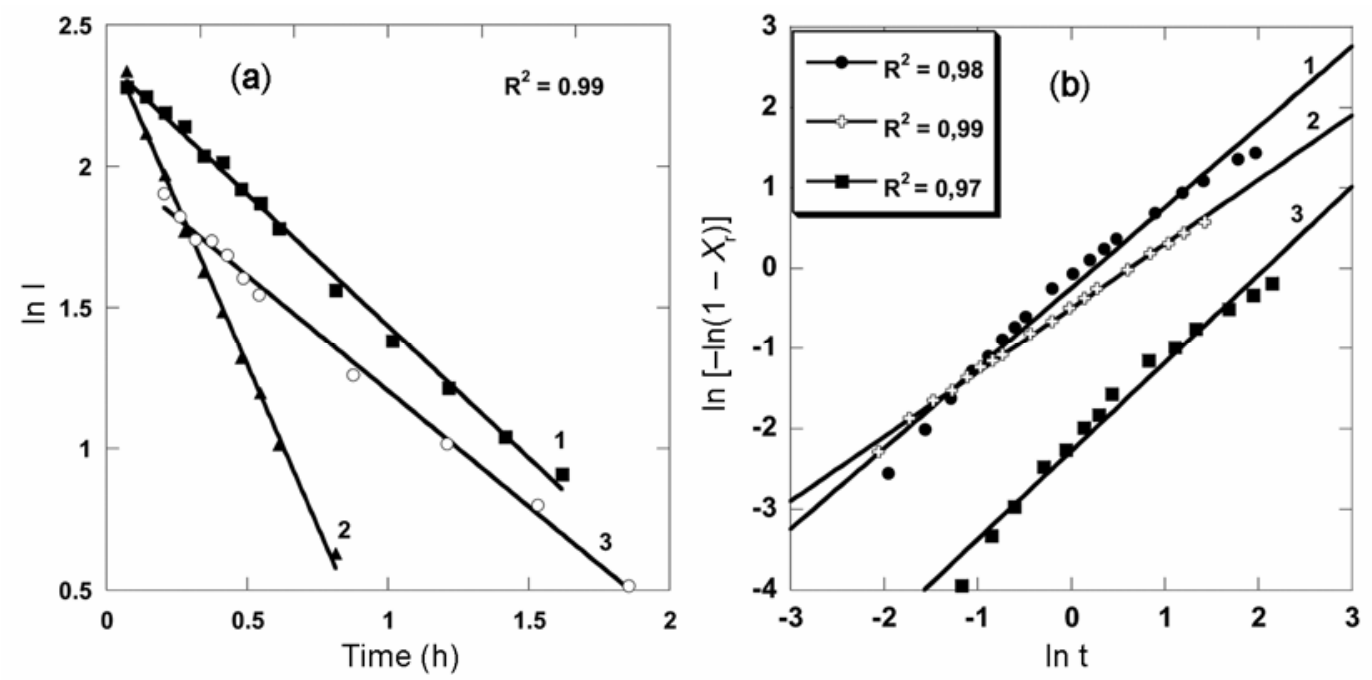

Figure 7. Transition kinetics order: $1 . \mathrm{TiO}_{2}\left(650^{\circ} \mathrm{C}\right) ; 2 . \mathrm{CrTi}_{5}\left(750{ }^{\circ} \mathrm{C}\right)$ and $3 . \mathrm{CrTi}_{20}\left(750^{\circ} \mathrm{C}\right)$.

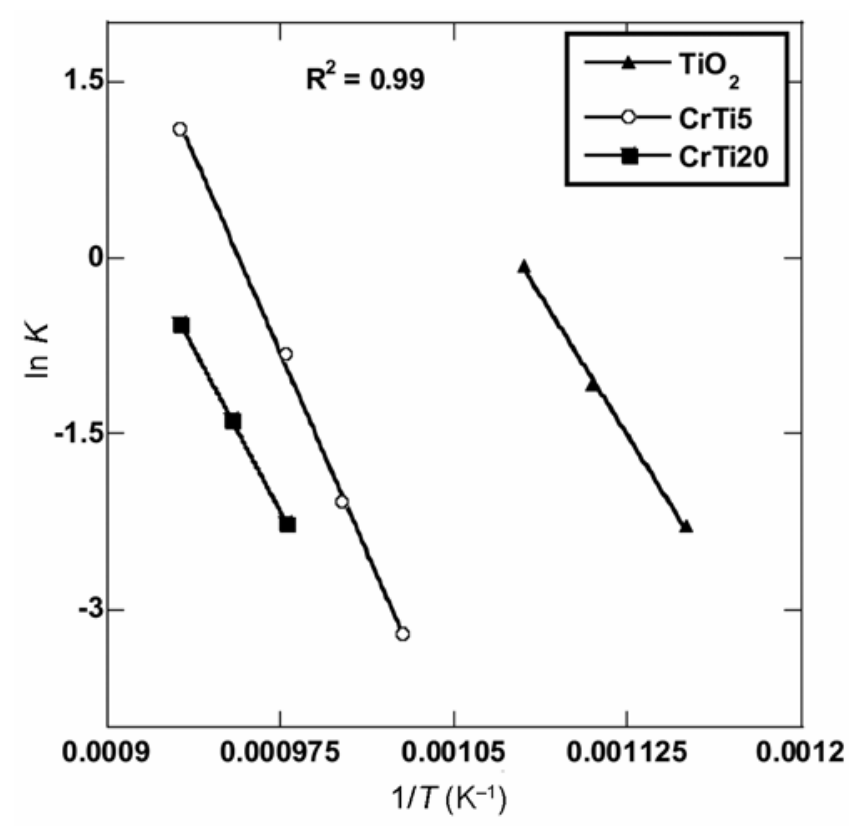

Figure 8. Transition anatase-rutile activation energy.

for $\mathrm{TiO}_{2}, \mathrm{CrTi}_{5}$ and $\mathrm{CrTi}_{20}$, respectively. The values of activation energy in the case of $\mathrm{TiO}_{2}, \mathrm{CrTi}_{5}$ and $\mathrm{CrTi}_{20}$ are 263, 375 and $308 \mathrm{~kJ} \mathrm{~mol}^{-1}$, respectively. As described above, the increase of chromium content retards the anatase-ritule transition so the activation energy increases with increase of chromium content. The calculated values of activation energy are in good correlation with increase of chromium content. There is a decrease in activation energy with increase of chomium content from 5 to $20 \%$. This decrease of activation energy is accompanied by decreasing of pre-exponential factor. Therefore, the presence of chromium increases the energy of anatase-rutile.

\section{Conclusions}

CrTi $X$ mixed oxides with $X=0,5,10$ and 20 of atomic chromium content was synthesized by sol-gel method. All the samples were characterized by means of some techniques (XRD, TGA/DTA and BET). The chromium content is crucial to the anatase phase stability, and the transition anatase-rutile depends on the heating temperature and chromium content. Without addition of chromium, the anatase phase is stable at low temperature $\left(400-500^{\circ} \mathrm{C}\right)$. The total anatase-rutile transformation was observed at $700{ }^{\circ} \mathrm{C}$. The crystallite size of anatase phase increases with increase of temperature from 400 to $700{ }^{\circ} \mathrm{C}$.

With addition of chromium, the anatase phase remains stable at $800{ }^{\circ} \mathrm{C}$. Chromium ions incorporated in $\mathrm{TiO}_{2}$ anatase phase delay the transformation to rutile and preserve smaller crystallite sizes thus inducing better catalytic activities such as hydrocarbon oxidation.

The kinetics of anatase-rutile transition obey the firstorder kinetics. Activation energy of the anatase-rutile transition increases in the presence of chromium.

\section{Electronic Supplementary Material}

Supplementary material pertaining to this article is available on the Bulletin of Materials Science website (www.ias.ac.in/matersci).

\section{References}

Aldabergenova S B, Ghicov A, Albus S, Macak J M and Schmuki P 2008 J. Non-Cryst. Solids 3542190

Arroyo R, Cordoba G, Padilla J and Lara V H 2002 Mater. Lett. 54397

Bacsa R R and Kiwi J 1998 Appl. Catal. B: Environ. 1619 
Baltazar P, Lara V H, Cordoba G and Arroyo R 2006 J. Sol-Gel Sci. Technol. 37129

Barakat M A, Schaeffer H, Hayes G and Ismat-Shah S 2005 Appl. Catal. B: Environ. 5723

Bellifa A, Lahcene D, Techenar Y N, Choukchou-Braham A, Bachir R, Bedrane S and Kappenstein C 2006 Appl. Catal. A: Gen. 3051

Chao H E, Yun Y U, Xingfang H U and Larbot A 2003 J. Eur. Ceram. Soc. 231457

Djaoued Y, Badilescu S, Ashrit P V, Bersani D, Lottici P P and Robichaud J 2002 J. Sol-Gel. Sci. Technol. 24255

Finnegan M P, Zhang H and Banfield J F 2007 J. Phys. Chem. C111 1962

Gambhire A B, Lande M K, Mandale A B, Patil K R and Arbad B R 2008 Philos. Mag. 88767

Ha P S, Youn H J, Jung H S, Hong K S, Park Y H and Ko K H, 2000 J. Colloid. Interf. Sci. 22316

Houskova V, Stengl V, Bakardjieva S, Murafa N and Tyrpekl V 2009 Appl. Catal. B. Environ 89613

Hu Y, Tsai H L and Huang C L 2003a Mater. Sci. Eng. A344 209

Hu Y, Tsai H L and Huang C L 2003b J. Eur. Ceram. Soc.23 691

Jiang X and Chen X 2004 J. Cryst. Growth 270547

Lee M S, Lee G, Ju C and Hong S 2005 Sol. Energ. Mat. Sol. C88 389

Li W, Ni C, Lin H, Huang C P and Shah S I 2004 J. Appl. Phys. 966663

Li J, Li Q, Ye Y and Hao Y 2011 J. Alloys Compd. 509 5532

Li Z, Hou B, Xu Y, Wu D, Sun Y, Hu W and Deng F $2005 J$. Solid State Chem. 1781395

Ma Q, Liu S J, Weng L Q, Liu Y and Liu B 2010 J. Alloys Compd. $\mathbf{5 0 1} 333$

Mahanty S, Roy S and Sen S 2004 J. Cryst. Growth 26177
Niemeyer D, Williams D E, Smith P, Pratt K F E, Slater B, Catlow C R A and Stoneham A M 2002 J. Mater. Chem. 12 667

Pavasupree S, Suzuki Y, Pivsa-Art S and Yoshikawa S 2005 J. Solid State Chem. 178128

Pillai S C et al 2007 J. Phys. Chem. C11 1605

Popa A F, Courtheoux L, Gautron E, Rossignol S and Kappenstein C 2005 Eur. J. Inorg. Chem. 543

Rajesh Kumar S, Pillai S C, Hareesh U S, Mukundan P and Warrier K G K 2000 Mater. Lett. 43286

Reddy B M, Ganesh I, Reddy E P, Fernandez A and Smirniotis P G 2001 J. Phys. Chem. B105 6227

Reidy D J, Holmes J D, Nagle C and Morris M A $2005 \mathrm{~J}$. Mater. Chem. 153494

Riays S, Krishnan G and Mohan Das P N 2007 Adv. Appl. Ceram. 106255

Ruiza A M, Sakai G, Cornet A, Shimanoe K, Morante J R and Yamazoe N 2003 Sens. Actuators B. Chem. 93509

Setiawati E and Kawano K 2008 J. Alloys Compd. 451293

Sreethawong T, Suzuki Y and Yoshikawa S 2005 J. Solid State Chem. 178329

Wang C, Li Q and Wang R 2004 Mater. Lett. 581424

Wetchakun N and Phanichphant S 2008 Curr. Appl. Phys. 8 343

Yoo K, Choi H and Dionysiou D D 2004 Chem. Commun. 2000

Zhang H and Banfield J F 1998 Mater. Res. Soc. 481619

Zhang H and Banfield J F 2005 Chem. Mater. 173421

Zhang H and Banfield J F 2000 J. Phys. Chem. B104 3481

Zhang Q, Li Q, Li J and Bai R 2011 Chinese J. Chem. Phys. 24 85

Zhang R B 2005 J. Non-Cryst. Solids 3512129

Zhu K R, Zhang M S, Hong J M and Yin Z 2005 Mater. Sci. Eng. A403 87

Zhuang K, Qiu J, Tang F, Xu B and Fan Y 2011 Phys. Chem. Chem. Phys. 134463 